\title{
Article \\ Can Nuclear Batteries Be Economically Competitive in Large Markets?
}

\author{
Jacopo Buongiorno ${ }^{1, *(1)}$, Ben Carmichael ${ }^{2}$, Bradley Dunkin ${ }^{3}$, John Parsons ${ }^{1}$ and Dirk Smit ${ }^{4}$ \\ 1 Massachusetts Institute of Technology, Cambridge, MA 02139, USA; jparsons@mit.edu \\ Southern Company, Atlanta, GA 30308, USA; bmcarmic@southernco.com \\ Advanced Manufacturing Solutions, Portland, OR 97086, USA; brad.d.dunkin@gmail.com \\ 4 Shell Global Solutions B.V., Grasweg 31, 1031 HW Amsterdam, The Netherlands; Dirk.Smit@Shell.com \\ * Correspondence: jacopo@mit.edu
}

check for

updates

Citation: Buongiorno, J.; Carmichael, B.; Dunkin, B.; Parsons, J.; Smit, D. Can Nuclear Batteries Be Economically Competitive in Large Markets? Energies 2021, 14, 4385. https://doi.org/10.3390/en14144385

Academic Editor: Steven E. Aumeier

Received: 17 May 2021

Accepted: 15 July 2021

Published: 20 July 2021

Publisher's Note: MDPI stays neutral with regard to jurisdictional claims in published maps and institutional affiliations.

Copyright: (c) 2021 by the authors. Licensee MDPI, Basel, Switzerland. This article is an open access article distributed under the terms and conditions of the Creative Commons Attribution (CC BY) license (https:// creativecommons.org/licenses/by/ $4.0 /)$.

\begin{abstract}
We introduce the concept of the nuclear battery, a standardized, factory-fabricated, road transportable, plug-and-play micro-reactor. Nuclear batteries have the potential to provide ondemand, carbon-free, economic, resilient, and safe energy for distributed heat and electricity applications in every sector of the economy. The cost targets for nuclear batteries in these markets are 20-50 USD/MWh $\mathrm{M}_{\mathrm{t}}(6-15 \mathrm{USD} / \mathrm{MMBTU})$ and 70-115 USD/MWh $\mathrm{M}_{\mathrm{e}}$ for heat and electricity, respectively. We present a parametric study of the nuclear battery's levelized cost of heat and electricity, suggesting that those cost targets are within reach. The cost of heat and electricity from nuclear batteries is expected to depend strongly on core power rating, fuel enrichment, fuel burnup, size of the onsite staff, fabrication costs and financing. Notional examples of cheap and expensive nuclear battery designs are provided.
\end{abstract}

Keywords: portable micro-reactors; cost of heat and electricity

In the U.S. there is growing support among policymakers and energy regulators for nuclear energy to play a substantial role in decarbonizing the global economic system. There is also recognition that the traditional nuclear deployment model based on field construction of large GW-scale reactors-taking over a decade to license and build, requiring multi-billion-dollar investments, and ultimately selling commodity electrons on the grid-is no longer economically sustainable. As such, considerable interest is now being placed on smaller reactors that can be deployed at a fraction of the cost and time and can serve a variety of users beyond the electric grid. In this paper we focus on micro-reactors, loosely defined as "nuclear reactors that have a thermal power of no more than tens of megawatts" [1].

The market potential of micro-reactors is vast and underestimated. Commonly emphasized applications include niche markets such as remote communities, mining sites and military bases, all applications in which nuclear would replace extremely expensive electricity supplied by diesel generators [2-4]. There are hundreds of such sites worldwide, thus targeting these niche applications is a wise first step toward commercialization of the micro-reactor technology. However, the full economic and environmental benefits of micro-reactors will not be realized unless they can displace fossil fuels in much larger markets and on a much grander scale. Industrial activities, transportation, buildings and agriculture account for over $70 \%$ of the world's total carbon emissions. Micro-reactors can supply electricity and heat to factories, manufacturing facilities, district heating, data centers, seaports and airports, ship propulsion systems, desalination plants, disaster relief efforts and EV recharging stations, to mention a few. They can do so without the massive infrastructure for energy storage and transmission which is typical of the electric grid and fossil fuel distribution networks [5].

In this paper, we first introduce a special class of micro-reactors that we will call Nuclear Batteries (NB) (Section 1) and discuss the scope of their potential markets (Section 2). 
Then we identify the NB cost targets for electricity and heat in those markets (Section 3). Finally, we present a parametric study of the NB's levelized cost of heat and electricity (Section 4) with the goal of (i) assessing whether those cost targets are within reach of the NB technology, and (ii) identifying its important cost drivers.

\section{The Nuclear Battery Concept}

A nuclear battery (NB) is defined here as a stand-alone, plug-and-play energy platform combining a micro-reactor and a turbine to supply significant amounts of heat and/or electricity from a very small footprint. It uses a factory-assembled, factory-fueled and road-transportable reactor design with a power output of 1 to $20 \mathrm{MW}$. It is compact enough to fit within ISO standard shipping containers and be transported to the site of interest, where it can be installed and be made operational in a matter of days to weeks. The NB is a semi-autonomous and remotely monitored system that can operate continuously or on demand for many years without fuel resupply. Once the NB is "exhausted," it can be replaced with a freshly fueled NB, while the used NB is safely shipped back to a central facility for refueling and refurbishment. As such, there is no need for high-level radioactive waste handling and storage at the user site, but a national waste repository is still required.

The concept of small portable plug-and-play micro-reactors is not new. In the early 1960s the U.S. Army designed, built and tested ML-1, a 500-kW gas-cooled micro-reactor that could be hauled around by truck and provide power in the field in less than a day and for over one effective full power year without refueling [6]. The Idaho National Laboratory currently defines a nuclear battery as a micro-reactor that is "cost competitive, fabricated, installed, unattended, reliable," akin to a AAA electrochemical battery. NBs are being designed to operate in either baseload or load-following mode. What makes the NB concept particularly compelling now is the maturation of a suite of technologies that will be used in modern NB designs, from advanced turbomachinery to sensors, from new nuclear materials to additive manufacturing, from machine learning to robotics.

The expected schedule for testing and commercialization of NBs is quite aggressive. For example, NBs for the Department of Defense's Project Pele are due for initial demonstration in 2023 and field deployment in 2027. Westinghouse's eVinci nuclear battery is scheduled to undergo nuclear testing at the Idaho National Laboratory in 2024. The KRUSTY/Kilopower NB for space applications, was designed, fabricated and tested by the Los Alamos National Laboratory and NASA in only three years, between 2015 and 2018. This represents a dramatic acceleration with respect to larger-scale reactors, including the so-called Generation IV systems.

Examples of modern NB designs are shown in Figure 1. None of these systems use traditional light-water-reactor technologies; all of them leverage significant innovations in coolant, fuel and moderator materials. In a common embodiment, the NB features a set of heat pipes that remove heat from a monolithic block-type reactor core in a manner that is insensitive to system orientation (important for mobile applications) and external perturbations. The reactor is encapsulated within a small and robust steel containment vessel, possibly embedded below grade. In general, the NB concept is expected to have an outstanding safety profile stemming from a combination of inherent features like accidenttolerant fuel form, low power density and high thermal capacity in the core, high surface-tovolume ratio to remove the decay heat, and few moving parts. The NB can achieve the three fundamental nuclear safety functions without operator intervention: (i) rapid shut down of the fission chain reaction in the event of an anomalous condition, (ii) adequate cooling of the nuclear fuel during shutdown, and (iii) no uncontrolled release of materials into the biosphere. This approach dramatically reduces by design the possibility of accidents like Three Mile Island, Chernobyl and Fukushima.

Physical security for NBs during operation will come from a combination of design features (e.g., robust fuel and reactor package), layout (e.g., below grade embedment) and remote monitoring and defense. For any autonomous system, cyber-security is also a potential concern. However, the NB's inherent safety features will be such that even 
a knowledgeable operator would not be able to damage the nuclear fuel or cause a radioactivity release. For example, it would be physically impossible to cause a runaway reaction (e.g., by manipulating control mechanisms), or use instrumentation and controls to interrupt residual heat removal from the core. While cyber-defense layers certainly must be implemented, they would be aimed primarily at ensuring continuity of service, not preventing a safety-relevant event.

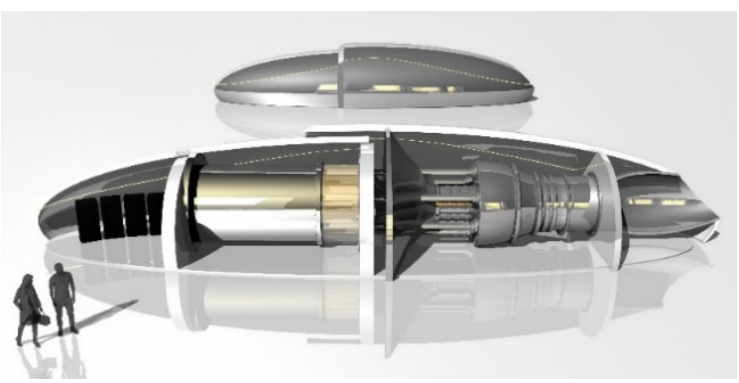

(a)

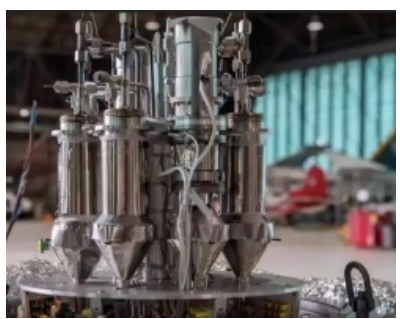

(c)

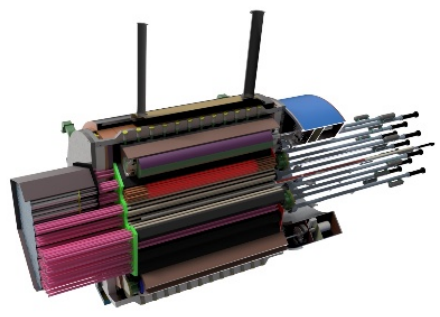

(d)

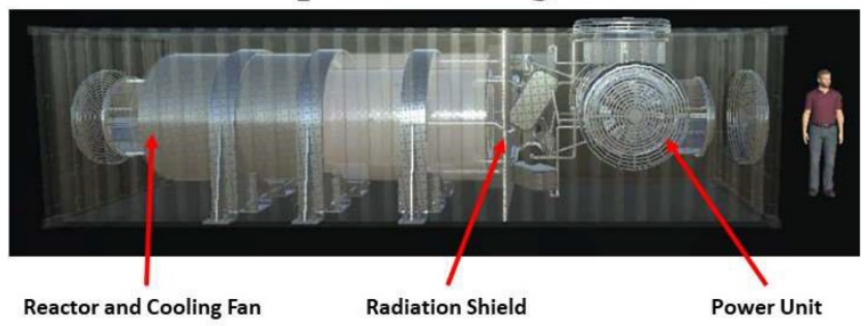

(b)

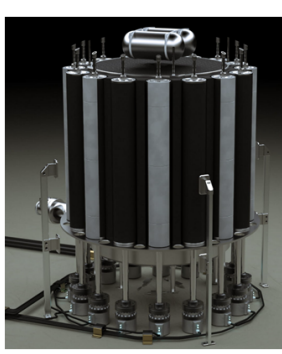

(e)

Figure 1. (a) MIT's conceptualization of a nuclear battery (NB) with integrated gas turbine; (b) LANL's Megapower [7]; (c) NASA and LANL's KRUSTY/Kilopower reactor using Stirling engine technology for space applications [8]; (d) Westinghouse's eVinci heat pipe micro-reactor [9]; (e) Radiant Nuclear's high-temperature gas-cooled micro-reactor [10].

For economic reasons, the NB site must require minimal preparation. Several aboveand below-grade layouts are possible, with different economic tradeoffs. For the purpose of this study, we envision excavation of a rectangular hole in the ground for a prefabricated steel/concrete vault which accommodates the NB. The NB reactor will be delivered to the site and lowered into the vault. Above grade there is a small flat area for the skidmounted power conversion unit and a small, prefabricated building-it could be another ISO container-which serves as an office and storage area for documentation, tools and materials required to perform minor maintenance on the NB. Depending on the nature and location of the site, a security fence may be required, or the NB could be sited directly within an already secure perimeter. Once the NB is exhausted, it will be lifted from the vault and shipped back to the central refueling and service facility. Layout examples for NBs are shown in Figure 2.

The promise and importance of the NB is most evident in comparison with other lowcarbon energy sources, which are generally of much lower power density. As such, NBs require considerably less space than solar and wind farms for the same power produced. For example, we estimate that ten 10-MW NBs, providing a stable energy supply of $100 \mathrm{MW}$, would occupy roughly $4000 \mathrm{~m}^{2}$ (including the security area), with an installed power density of $25,000 \mathrm{~W} / \mathrm{m}^{2}$. By comparison, a 100-MW wind farm of 3-MW turbines placed in a square grid has an installed power density of about $2-3 \mathrm{~W} / \mathrm{m}^{2}[11,12]$, and thus occupies at least $33,000,000 \mathrm{~m}^{2}$, often in dual use with agriculture. Offshore wind does not consume land but is subject to other geographic constraints. A notional size comparison between NBs and land-based renewables is shown Figure 3. 

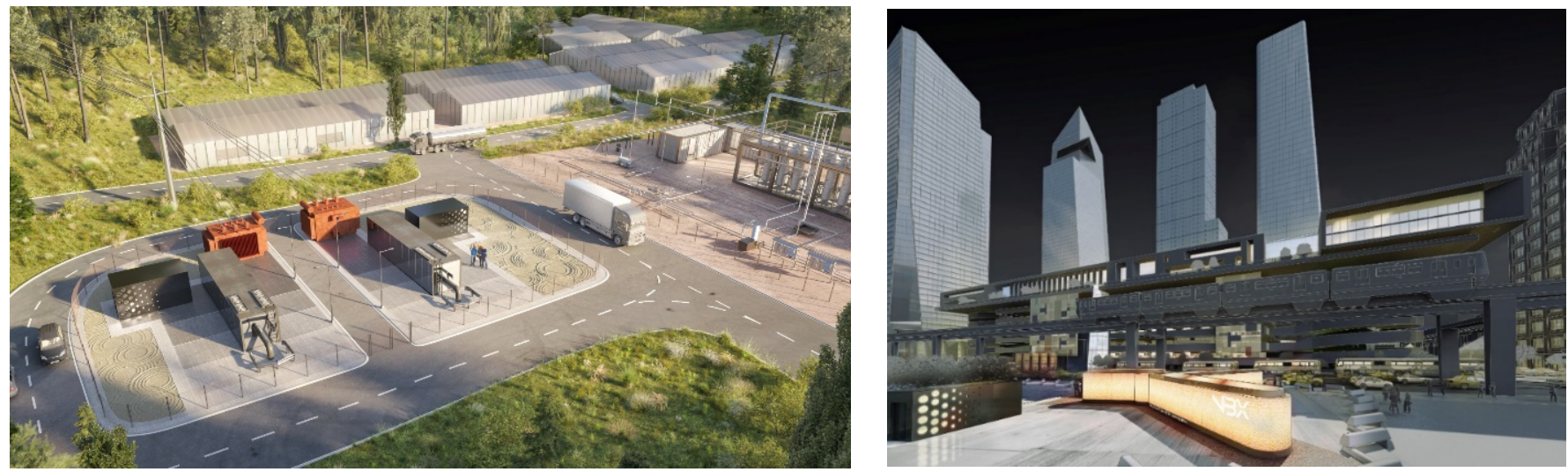

Figure 2. Examples of functional layout for (left) industrial and (right) urban NB installations. A single 10 MW NB can power some 7000-8000 homes or a large shopping mall or a mid-size data center, or produce enough desalinated fresh water for over 150,000 people.
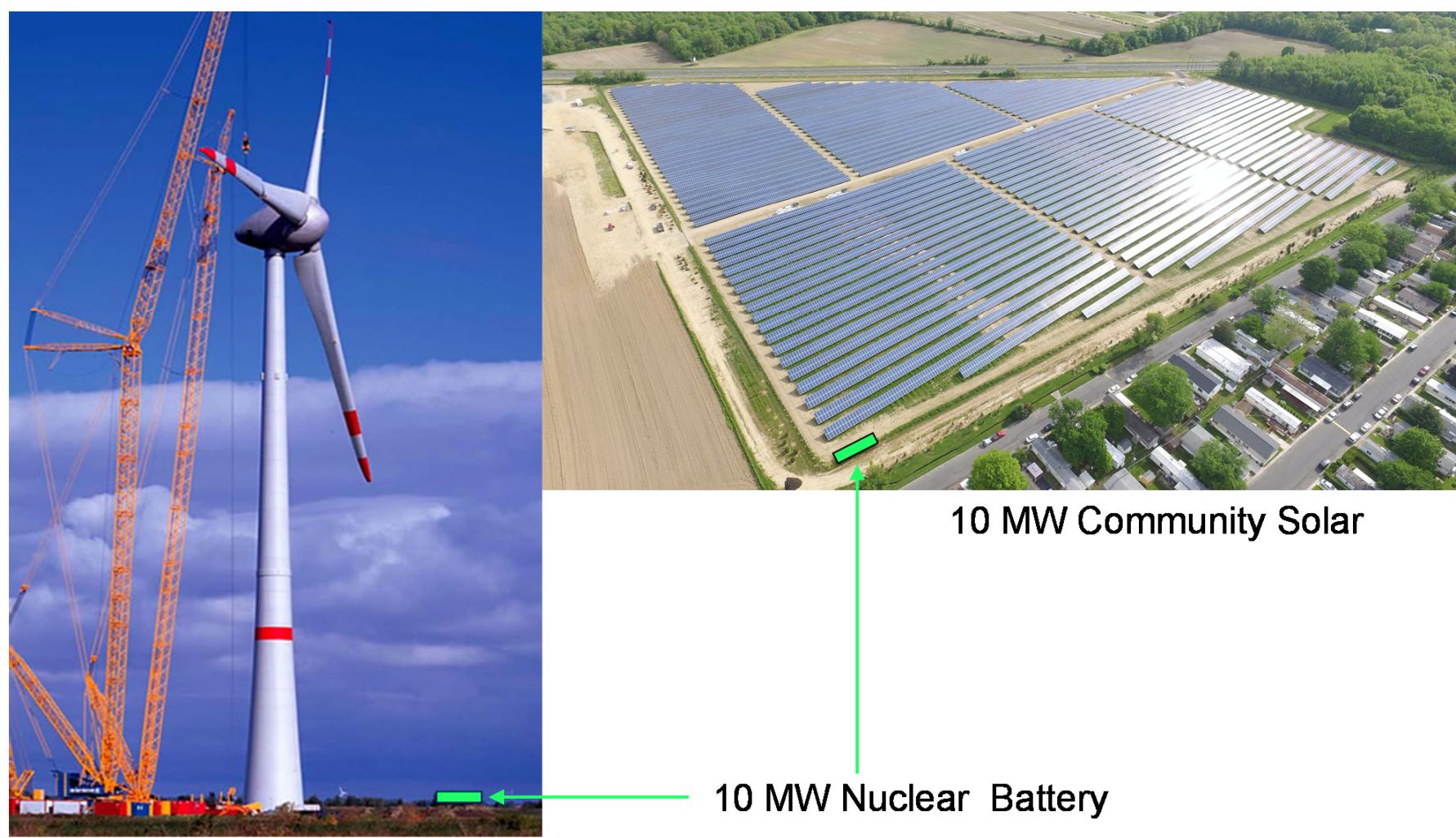

10 MW Community Solar

10 MW Vestas

Figure 3. Size comparison of a $10 \mathrm{MW}$ NB (green rectangle) vs. $10 \mathrm{MW}$ of wind (Vestas 164) and $10 \mathrm{MW}$ of solar (NJ Altus solar farm).

To build a wind farm of $100 \mathrm{MW}$ requires about 20,000 tons of steel, 50,000 tons of concrete as well as 900 tons of plastics used in the blades [13]. Solar PV farms of similar installed power would require 50\% larger total amount of material, albeit less steel than wind [14]. In contrast, we estimate that ten NBs generating $100 \mathrm{MW}$ would require about 20 tons of low enriched uranium, as well as about 1600 and 4600 tons of steel and concrete, respectively, which include the transportation cask and dry casks for the spent fuel. Moreover, while the capacity factor for a nuclear system is high, typically around 0.9 , the capacity factor of wind and solar PV farms is generally low, typically 0.35 and 0.2 , respectively, and varying seasonally which requires significant storage capacity to be 
installed alongside. Therefore, the $10 \mathrm{NBs}$ are actually equivalent to a wind plant of nominal capacity $260 \mathrm{MW}$ or a solar plant of nominal capacity $450 \mathrm{MW}$, and the aforementioned material requirements for wind and solar need to be scaled up accordingly for a meaningful comparison. Finally, NBs do not need energy storage systems alongside, can operate in short time, can be installed near the users and thus require no transmission expense. This makes them uniquely versatile and flexible to use for a wide variety of markets, as explained in the next section.

\section{Prospective Markets for Nuclear Batteries}

Nuclear batteries may offer a competitive source of energy for a number of diverse markets. Before turning to those markets, it is useful to focus first on the distinctive features of NBs and how that positions them against alternatives. Five distinct features determine where NBs are most likely to penetrate the market. The first is energy density, for both heat and electricity. The second is dispatchability, i.e., the ability to supply energy on demand. The third is zero emissions, including both carbon and local air pollutants such as particulates, NOx and SOx. The fourth is siting flexibility with minimal geographic constraints. The fifth is suitability for mobile deployment, which might be important in certain applications, for example ship propulsion. The first two features make NBs a direct competitor to fossil fuel-fired technologies, while the third and fourth give it a competitive advantage over them. Although NBs and fossil fuel-fired technologies are all dispatchable, the capital intensity of NBs means that their competitive advantage will be largest in serving baseloads, and smallest where the average capacity factor is low.

Renewables are a source of zero-emissions electricity for many loads and markets. They have supplanted significant quantities of fossil fuel-fired generation where emissions reductions have been prioritized. However, to get to a net-zero energy system will require a much larger penetration of zero-emissions technologies, and renewables are less well suited for some markets. NBs will be competitive against renewables wherever the demand for heat, for energy density, for dispatchability and for siting without geographic constraints are significant. Table 1 summarizes the comparison of NBs with potential alternatives.

Table 1. Energy source features for the 21st century energy markets.

\begin{tabular}{|c|c|c|c|c|c|}
\hline Energy Source & Energy Density $^{a}$ & Dispatchability & Zero Emissions & $\begin{array}{l}\text { Geographically } \\
\text { Unconstrained }\end{array}$ & $\begin{array}{c}\text { Suitable for Mobile } \\
\text { Deployment }\end{array}$ \\
\hline Nuclear (traditional) & High & Yes & Yes & No & No \\
\hline Nuclear (NBs) & High & Yes & Yes & Yes & Yes \\
\hline Natural gas & Medium & Yes & No & Yes ${ }^{b}$ & Yes \\
\hline Coal & Medium & Yes & No & Yes ${ }^{b}$ & No \\
\hline Hydro & Low & Yes & Yes & No & No \\
\hline Solar/Wind & Low & $\mathrm{No}^{c}$ & Yes & No & No \\
\hline
\end{tabular}

${ }^{a}$ Land area usage and materials consumption per unit energy generated. ${ }^{b}$ Fuel delivery and cooling requirements may impose significant constraints in certain regions. ${ }^{c}$ May become more dispatchable over short periods of time (hours) with improving storage technologies.

This catalogue of competitive advantages leads us to identify a diverse set of customers most likely to benefit from the NB technology.

Off-grid electricity markets are an obvious choice for first-mover NB customers. These markets typically rely on more expensive fossil fuels such as diesel, and the high cost of fuel delivery adds to unit costs. This raises the cost target a NB must achieve to be competitive against fossil fuel technologies. Success in this market, however, will depend significantly on vendors' success in making NBs a reliable option. Off-grid markets are often remote, and this impedes timely servicing or unscheduled replacement of whatever technology is installed. Consequently, off-grid markets often invest in duplicate capacity and place a premium on simple, familiar equipment such as diesel generators. They will have to be convinced that NBs can provide comparable reliability, recognizing logistical issues.

NBs also have strong potential as generation sources within microgrids. The value proposition of a microgrid is predicated in large part on the ultra-high reliability and 
resiliency of service they afford their owners and users. Highly reliable and dispatchable fossil-based generators are used with onsite fuel storage to match the energy-demand risk profile of the application. As a result, fossil generation constitutes over $85 \%$ of the capacity built into microgrids as of 2020. Only NBs can provide a highly reliable, high-capacity factor, fuel-secured, carbon-free alternative to fossil that provides resiliency of service and flexibly following the demand of a microgrid. Microgrids will become ubiquitous as certain areas of the electricity grid become more fragile and as transmission and distribution development costs rise over time. As the need to decarbonize continues concurrent with these trends, the need for NBs in microgrids will crystalize.

Heat markets, including industrial process heat and concentrated residential and commercial districts, have been served almost exclusively by a variety of fossil fuels, whether dedicated to the provision of heat or used for cogeneration of heat and electricity (CHP). In recent decades, natural gas (NG)-fired boilers have become the main option for heat users; similarly, NG-fired gas turbines and combined-cycle plants have become the main options for new, large-capacity CHP installations, while micro-turbines began to penetrate the market for very small CHP installations. However, in recent years, tightening carbon emissions goals have already dramatically reduced the outlook for any new CHP capacity in the U.S. and Europe, and have begun to spotlight the need for a zero-emissions option for dedicated heat production, too. This is a market in search of new options like NBs, and NBs will compete here against other new technologies. In the case of large-scale dedicated heat production or large-scale CHP, these may include NG with carbon capture and sequestration (CCS) or green hydrogen. In smaller commercial systems, this may include grid-supplied heat pumps. The same competitive requirements apply to heat applications, i.e., energy density, dispatchability, zero-emissions, and uniquely important for heat, proximity to the end users because of the large penalty associated with longdistance heat transmission. Since NBs can satisfy all these requirements simultaneously, heat markets represent a potentially enormous opportunity for NBs.

In summary, as compact, clean and dispatchable generators of heat and electricity, NBs can serve many markets and many activities across all sectors of the economy. Some examples are shown in Figure 4. Co-locating supply (the NB) and demand (the production facilities) maximizes the utilization factor of the energy generators and production facilities simultaneously, and drastically reduces the need for the massive energy transmission and storage infrastructure typical of the traditional power grid and fuel distribution networks.

The vision described here implies a future in which NBs will not be sited solely in isolated communities or remote areas for niche applications, but rather primarily in urban, suburban, industrial and coastal environments, therefore within or in proximity to densely populated areas, and would constitute the backbone of a new, more efficient and cleaner way to produce goods, foods and fuels. 


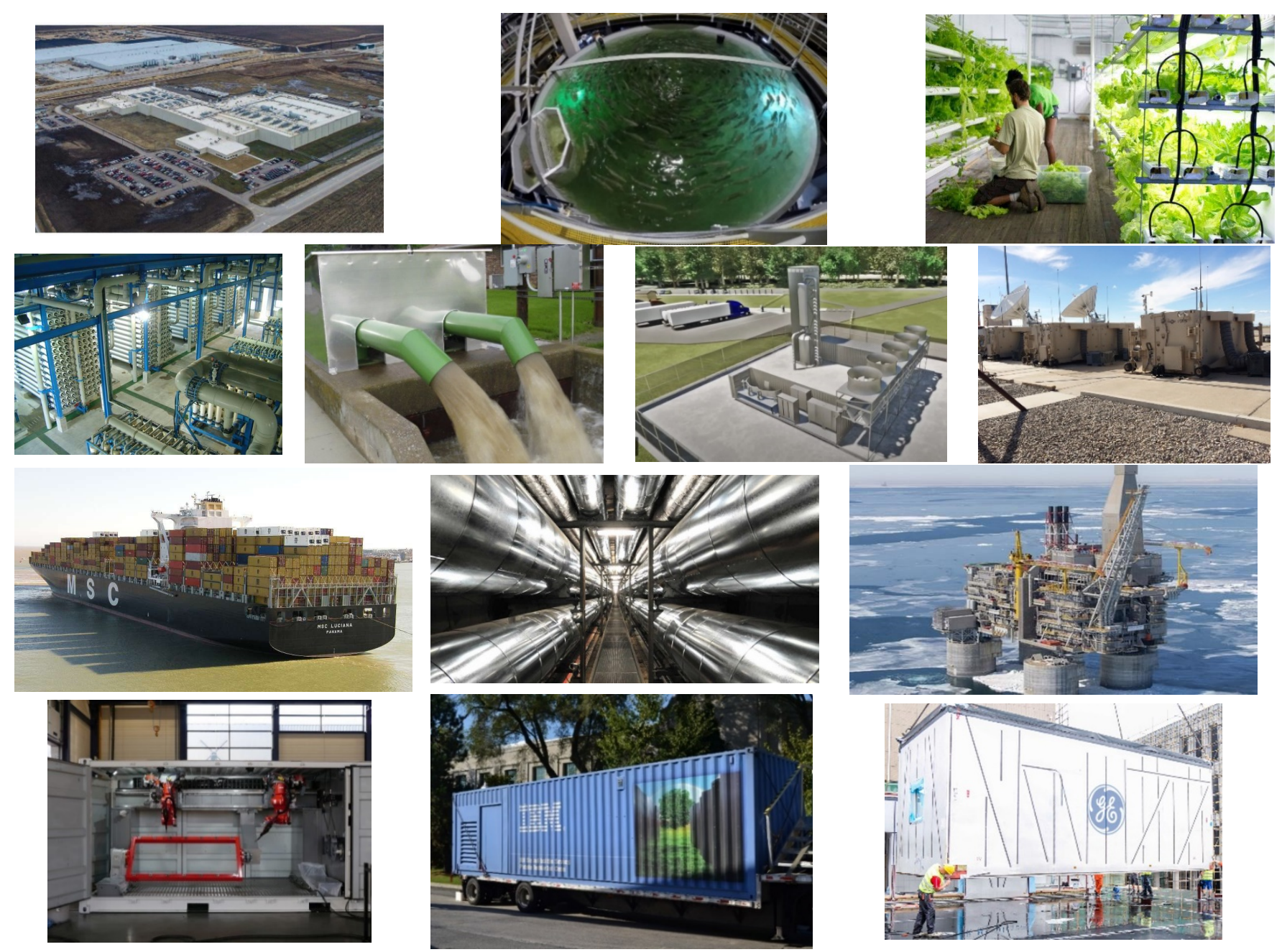

Figure 4. NBs could generate electricity and/or heat for myriad of collocated facilities. From top to bottom, left to right: process heat for factories, indoor aquaculture, containerized farming, water desalination units, pumps for flood protection, charging stations for e-trucks and hydrogen vehicles, military bases, freight ship propulsion, district heating, offshore oil/gas platforms, large 3D printing facilities, portable data centers and pharma manufacturing.

\section{Cost Targets for Nuclear Batteries in Large Markets}

The cost at which NBs become competitive varies greatly across the diverse array of markets and customers discussed in the previous section. At a higher cost, NBs are limited to a smaller market segment, and as NB costs fall with successive deployments, the scale of the market expands. Their competitiveness would increase further should the price of NG rise or the carbon abatement regulations (e.g., price signal via carbon tax, cap-and-trade or an emission limit) manifest. In order to provide useful targets, here we focus on three benchmarks.

The first benchmark is the cost of NG used to provide direct heat production, inclusive of a cost of carbon. In the U.S. and many regions of the world, the competition for NBs in heat applications will be NG-fired boilers. Table 2 shows the average prices of NG in the U.S. Most NG boilers are too small for carbon capture and sequestration (CCS). As such, burning NG will result in substantial emissions and, in a carbon-constrained world, will incur a carbon tax. Interestingly, should CCS be an option, its cost for a flue gas with $10 \%$ mol. $\mathrm{CO}_{2}$ concentration and $99 \%$ capture efficiency could be up to $100 \mathrm{USD} / \mathrm{t}_{\mathrm{CO}}$, [15] including compression, but excluding transport and storage, which might add an extra 4-45 USD/ $\mathrm{t}_{\mathrm{CO} 2}$ depending on location [16]. Figure 5 shows the cost of heat from NG as a function of NG price for various values of the carbon tax from 50 to $150 \mathrm{USD} / \mathrm{t}_{\mathrm{CO} 2}$. 
Examination of these plots suggests that the competitive cost target for heat from the NBs should be in the 20-50 USD/MWh (6-15 USD/MMBTU) range.

Table 2. Average natural gas (NG) prices in the U.S. (USD/MMBTU) (Source EIA).

\begin{tabular}{lcccccc}
\hline & $\mathbf{2 0 1 4}$ & $\mathbf{2 0 1 5}$ & $\mathbf{2 0 1 6}$ & $\mathbf{2 0 1 7}$ & $\mathbf{2 0 1 8}$ & $\mathbf{2 0 1 9}$ \\
\hline Residential & 10.6 & 10.0 & 9.7 & 10.5 & 10.1 & 10.1 \\
Commercial & 8.6 & 7.6 & 7.0 & 7.6 & 7.5 & 7.3 \\
Industrial & 5.4 & 3.8 & 3.4 & 3.9 & 4.0 & 3.8 \\
\hline
\end{tabular}

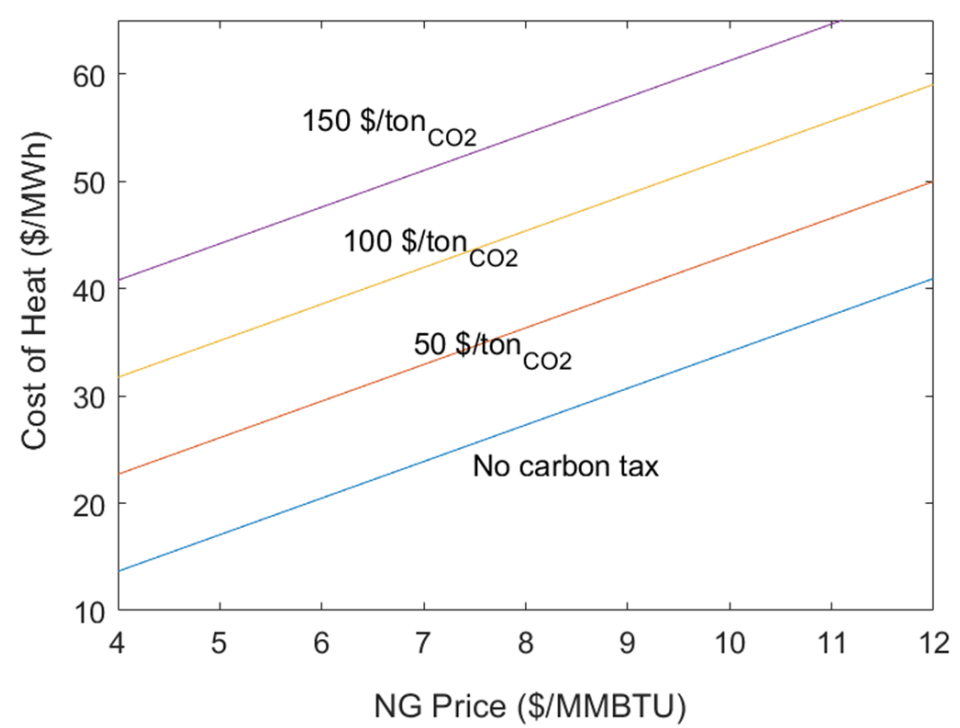

Figure 5. The cost of heat from NG as a function of NG price and carbon tax. The cost of the boiler is not included.

The second benchmark is the cost of dispatchable electricity, whether from a large NG combined-cycle generator (NGCC) or from NG-fired distributed generation, both inclusive of a cost of carbon. We used the assumptions made in the EIA's 2021 Annual Energy Outlook to calculate the levelized costs of electricity (LCOE) for a NGCC as a function of the NG price and carbon tax. The EIA Outlook modeling also includes a "generic" dispatchable generator operating at baseload. Installation of the dispatchable generator helps avoid transmission investments. The EIA's modeling shows significant amounts of this dispatchable generation installed. We calculate the LCOE for this NG-fired distributed generator operating baseload as a function of the NG price and carbon tax and treat this as a benchmark for the higher value end of the market where a NB can compete. The results are shown in Figure 6.

This second benchmark shows that at a natural gas price of $4 \mathrm{USD} / \mathrm{MMBTU}$ and a carbon price of $100 \mathrm{USD} /$ ton $_{\mathrm{CO} 2}$, the LCOE for baseload generation by an NGCC plant is about $70 \mathrm{USD} / \mathrm{MWh}$ and the LCOE for baseload generation by NG-fired distributed generation is about $115 \mathrm{USD} / \mathrm{MWh}$. Therefore, 70-115 USD/MWh can be considered a reasonable cost target range for electricity generation by the NBs. 


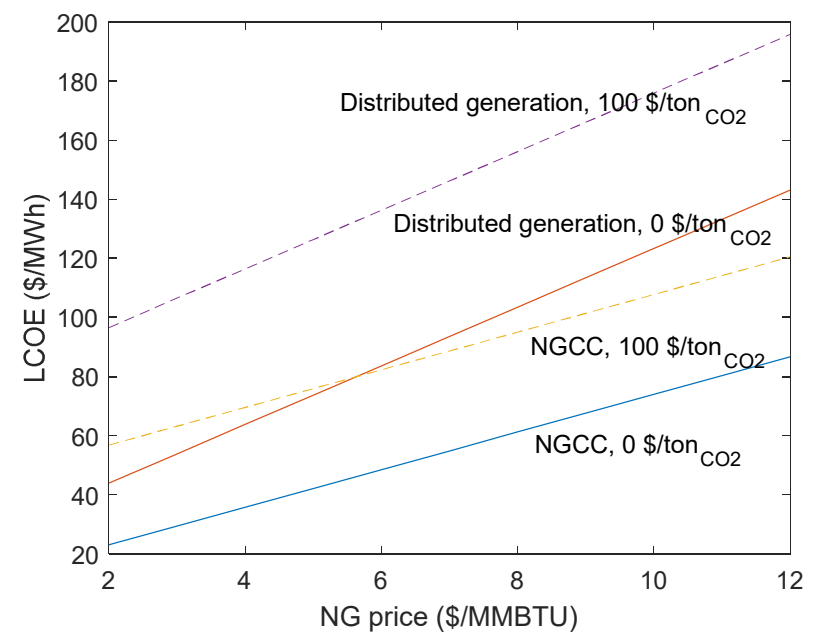

Figure 6. The levelized costs of electricity (LCOE) for two types of NG-fired generation as a function of NG price and carbon tax. Calculations are based on the assumptions from the EIA's 2021 Annual Energy Outlook.

The third benchmark is the cost of generating hydrogen. We consider two low-carbon production routes to hydrogen that would have the potential to produce at scale within a reasonable time. One route involves the steam methane reforming process with CCS, while the other route is through renewable power coupled with electrolysis of water. Of these two, methane reforming followed by CCS (presumably at $>95 \%$ capture efficiency) is closest to deployment at scale. Assuming a carbon tax of $100 \mathrm{USD} / \mathrm{t}_{\mathrm{CO} 2}$ and NG price of $3 \mathrm{USD} / \mathrm{MMBTU}$, the projected cost of hydrogen is about $1 \mathrm{USD} / \mathrm{kg}$, excluding storage and distribution costs. This cost may escalate to about $3 \mathrm{USD} / \mathrm{kg}$ or higher if carbon capture efficiency needs to be better than $98 \%$, which may be required to avoid unacceptable increases in level of atmospheric $\mathrm{CO}_{2}$ due to hydrogen production. In contrast, the renewable power plus electrolysis route has more uncertainties given the lack of experience with deployment at scale. For example, it is unclear how to realistically factor in the costs of storing electricity and/or the hydrogen itself needed to cope with the inherent intermittency of renewable power. Assuming a levelized cost of electricity of $50 \mathrm{USD} / \mathrm{MWh}$, the current estimated cost of hydrogen produced from renewables is $4-5 \mathrm{USD} / \mathrm{kg}$, excluding hydrogen distribution costs. It thus seems that the cost of hydrogen obtained from a high-temperature electrolysis process powered by NBs would need to be in the 3-4 USD $/ \mathrm{kg}$ range to become competitive with these alternative routes.

\section{Evaluation of the Cost of Electricity and Heat from Nuclear Batteries}

In this analysis, we assume that the NB is shipped with a fueled core, is operated continuously for several years, and then is shipped back to a central facility for refueling and servicing. There is no refueling at the site, but there can be short maintenance outages with an associated loss of generation (accounted for by the capacity factor). This model of deployment, operations and service affects some aspects of the economic analysis that we are about to describe.

The levelized costs of electricity (LCOE) and heat $(\mathrm{LCOH})$ for the NB are equal to the sum of the annualized capital costs, fuel costs and O\&M costs divided by the total amount of electricity or heat generated in one year:

$$
\begin{aligned}
\mathrm{LCOE} & =\frac{\text { Annualized Fuel }+ \text { O\&M }+ \text { Capital Costs }}{\text { Electric power } \times \text { capacity factor } \times 8760}[\mathrm{USD} / \mathrm{MWh}] \\
\mathrm{LCOH} & =\frac{\text { Annualized Fuel }+ \text { O\&M }+ \text { Capital Costs }}{\text { Thermal power } \times \text { capacity factor } \times 8760} \quad\left[\mathrm{USD} / \mathrm{MWh}_{\mathrm{t}}\right]
\end{aligned}
$$


Since a nuclear reactor is a heat source, nuclear heat is always cheaper than nuclear electricity, i.e., $\mathrm{LCOH}<\mathrm{LCOE}$.

The baseline case assumptions used in the analysis are reported in Table 3. The three cost components are next discussed one at a time. The cost calculations are performed using the MATLAB script reported in the Appendix A. Development and regulatory costs are not considered in this analysis.

Table 3. Baseline assumptions for the NB cost analysis.

\begin{tabular}{|c|c|c|}
\hline Parameter & Value & Notes \\
\hline electric power output & $10 \mathrm{MW}$ & $\begin{array}{l}\text { Reasonable value for many NB } \\
\text { applications. Varied in sensitivity analysis. }\end{array}$ \\
\hline thermal efficiency & $35 \%$ & $\begin{array}{c}\text { Estimated for open-air Brayton cycle with } \\
\text { heat recuperation and losses in } \\
\text { turbomachinery and piping }\end{array}$ \\
\hline core power & $28.6 \mathrm{MW}$ & $=$ electric power/thermal efficiency \\
\hline refueling interval & 5 years & $\begin{array}{l}\text { From outage to outage. Varied in sensitivity } \\
\text { analysis. }\end{array}$ \\
\hline capacity factor & $93 \%$ & $\begin{array}{l}\text { Translates to } 4 \text { months of effective } \\
\text { downtime due to unanticipated loss of } \\
\text { availability during operation. Varied in } \\
\text { sensitivity analysis. }\end{array}$ \\
\hline refueling and servicing downtime & 6 months & $\begin{array}{l}\text { Includes NB cooling time onsite and } \\
\text { roundtrip to refueling and servicing facility }\end{array}$ \\
\hline fuel enrichment & $5 \%$ & $\begin{array}{c}\text { Does not require relicensing of U.S. fuel } \\
\text { cycle facilities. Varied in sensitivity } \\
\text { analysis. }\end{array}$ \\
\hline discharge burnup & $15 \mathrm{MWd} / \mathrm{kg}_{\mathrm{U}}$ & $\begin{array}{l}\text { Lower than LWR because of small cartridge } \\
\text { core. Varied in sensitivity analysis. }\end{array}$ \\
\hline cost of uranium & $40 \mathrm{USD} / \mathrm{lb}$ of $\mathrm{U}_{3} \mathrm{O}_{8}$ & $\begin{array}{l}\text { Conservative assumption for cost of yellow } \\
\text { cake }\end{array}$ \\
\hline cost of uranium conversion & $6 \mathrm{USD} / \mathrm{kg}_{\mathrm{U}}$ & $\begin{array}{l}\text { Conservative assumption for cost of } \\
\text { converting yellow cake into } \mathrm{UF}_{6}\end{array}$ \\
\hline cost of uranium enrichment & $160 \mathrm{USD} / \mathrm{SWU}$ & $\begin{array}{c}\text { Conservative assumption in current } \mathrm{U} \\
\text { market }\end{array}$ \\
\hline cost of fuel fabrication & $500 \mathrm{USD} / \mathrm{kg}_{\mathrm{U}}$ & $\begin{array}{l}2 \times \text { higher than traditional LWR fuel } \\
\text { fabrication }\end{array}$ \\
\hline cost of spent fuel disposal & $1 \mathrm{USD} / \mathrm{MWh}$ & U.S. spent nuclear fuel disposal fee \\
\hline \# of FTE for O\&M & 5 & $\begin{array}{c}\text { Same FTE/MW of current U.S. fleet. Varied } \\
\text { in sensitivity analysis. }\end{array}$ \\
\hline compensation per FTE & 150,000 USD/year & Includes benefits and taxes \\
\hline other fixed O\&M costs & $0.5 \mathrm{M} \mathrm{USD} /$ year & $\begin{array}{c}\text { Includes NRC operating fees, NRC } \\
\text { inspections, insurance premium and } \\
\text { property taxes }\end{array}$ \\
\hline capital costs & 30 M USD & $\begin{array}{l}3000 \text { USD / kW. Includes reactor and power } \\
\text { conversion unit fabrication, transportation, } \\
\text { installation and connection, site } \\
\text { preparation and service building. Excludes } \\
\text { fuel costs. Varied in sensitivity analysis. }\end{array}$ \\
\hline NB economic lifetime & 20 years & NB technical lifetime likely longer \\
\hline cost of decommissioning & $1 / 2$ capital costs & Incurred at the end of the project \\
\hline discount rate & $6 \% /$ year & $\begin{array}{l}\text { Consistent with EIA's assumption for the } \\
\text { weighted average cost of capital of new } \\
\text { energy technologies [17]. Varied in } \\
\text { sensitivity analysis. }\end{array}$ \\
\hline
\end{tabular}




\subsection{Fuel Costs}

Since the core power, the discharge burnup, the refueling interval and the capacity factor are fixed, the mass of fuel in the core is also immediately found.

The amount of natural uranium feed and the SWU required per $\mathrm{kg}$ of fuel in the core are calculated from the known fuel enrichment (5\%), and assuming $0.22 \%$ enrichment for the uranium tailings.

The baseline NB is assumed to use uranium dioxide fuel, at twice the fabrication cost compared to a LWR fuel assembly because of the likely differences in pellet dimensions, cladding material and fuel assembly design adopted in the NB.

The costs of natural uranium, uranium conversion, enrichment and fuel fabrication are summed up and levelized over the refueling interval. Since all these fuel costs are incurred at the start of an irradiation cycle, there are carrying charges that must be accounted for using a capital recovery factor at the assumed discount rate.

The cost of spent fuel disposal is assumed to be 1 USD/MWh, consistent with U.S. practice.

\subsection{OEM Costs}

Given the simplicity of the NB design and the adoption of dry cooling, we do not anticipate major materials costs associated with operations of the NB. Therefore, the O\&M costs primarily include the labor charges for staff required to operate, inspect and service the NB and to provide a proper level of security at the site. These charges are very uncertain at the moment; for example, it is unclear whether onsite operators are required at all, or autonomous operation with remote control may be feasible. It is also unclear whether adequate security can be maintained with physical protection and remote surveillance alone or if onsite armed guards will be required. In the base case we assume the total size of the NB staff to be 5 FTEs, effectively equivalent to one person on site 24/7. The fully loaded cost of each FTE is $150 \mathrm{kUSD} /$ year. Note that fairly large and complex NG-fired power plants power plants are now being commissioned to operate with no onsite operators [18].

Other O\&M fixed costs include NRC operating fees, NRC inspections, insurance premiums and property taxes. Using the MIT research reactor as an analogue, we conservatively estimate such costs to be about $0.5 \mathrm{M}$ USD/year.

\subsection{Capital Costs}

This category includes site preparation, equipment fabrication, transportation, installation and decommissioning costs. To facilitate the description of these costs, we make use of the terminology shown in Figure 7.

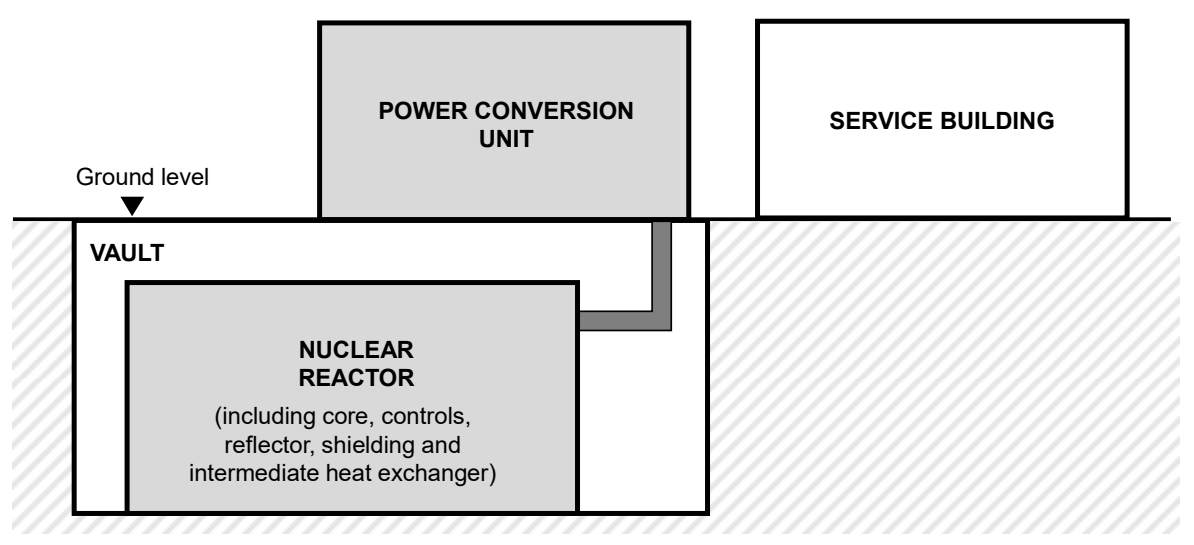

Figure 7. Basic elements of a NB site with below-grade micro-reactor.

The NB site will require minimal preparation, in part because the NB will be designed with inherent features (e.g., dry cooling, seismic robustness) to fit a large set of sites without modification. We envision excavation of a rectangular hole in the ground for a prefabricated steel/concrete vault, which will accommodate the nuclear reactor. Above grade there is a 
small flat area for the power conversion unit, permanent plant equipment (all delivered on their individual skids) and a small, prefabricated service building for security and staffing which will also serve as office and storage area for documentation, tools and materials required to perform minor maintenance on the NB. Depending on the nature and location of the site, a dedicated fence around the plant may be required.

The fabrication cost of the NB, including its power conversion unit (but excluding the fuel), is highly uncertain. At this stage of NB maturity, there are multiple designs being considered for development. Each will have differing core designs, power conversion units, market focus and operational considerations. To evaluate the potential costs of the $\mathrm{NB}$, we choose a baseline design concept employing a solid core with heat pipes and an air-breathing Brayton power conversion unit.

For guidance on process and to assure the reasonableness of our cost projections, we rely on the Standard Classification for Cost Estimate Classification System, ASTM E-2516 classifications and guidance for methodology and definitions. Based on the design maturity, the estimating process used is the "Analogy" method for this Class 5 or concept screening estimating effort. However, the analogy method is problematic in estimating the micro-reactor costs because there is limited data upon which to define and leverage any analogy. The closest analogue is probably a large jet engine, GE-90, which is a delicate and complex machine generating about $80 \mathrm{MW}$ peak mechanical power at takeoff, which costs $28 \mathrm{M}$ USD or $350 \mathrm{USD} / \mathrm{kW}$. While the GE-90 engine is larger and more powerful than our $\mathrm{NB}$, as engines become smaller and less powerful, cost per MW increases. We therefore use $500 \mathrm{USD} / \mathrm{kW}$ as a conservative analogy.

To develop our cost projections, we leverage actual costs of a GE-90 jet engine with adjustments, or estimates, to account for differences between the analogue of the baseline and any unique systems. While a large jet engine such as the GE-90 engine powering the Boeing 777 is different in almost every way from our NB, its manufacturing system complexities, tolerances and demands are extensive and pertinent to the NB.

We do anticipate that the assembly, testing and materials for jet engines are consistent with the manufacturing requirements anticipated for a NB. The turbine rotating components are different from a NB, meaning that the tolerances, assembly requirements, internal temperatures and instrumentation provide a valid comparison if and only if components such as pressure vessels, heat exchangers, shielding, heat pipes, moderators and coolants are separately estimated. Our estimates make allowances for those unique features.

The expectation is that such a micro-reactor could benefit greatly from high-volume fabrication in factories, however that has not been demonstrated in a nuclear manufacturing environment. To achieve the production rates upon which our fabrication cost estimates are founded, we rely on knowledgeable fabricators and a mature supply chain. There remain risks in the fabrication and supply chain based on the current state of the nuclear industry resulting from the cost and schedule overruns experienced by recent large-scale reactor projects in the US. However, the basic concept of the NB minimizes those risks by maximizing the commercial-grade content of the equipment, and fully leveraging factory manufacturing, learning and automation. With development, we believe that efficiencies comparable to other industries can be realized. The unique features of our NB estimates are based on preliminary design information, vendor quotes and recognized estimating standards where applicable.

The nuclear reactor will be delivered to the site in one piece and lowered into the vault. The cost of transportation for the reactor, the vault, the power conversion unit and the service building will depend on their weight and means of access to the site (road, rail, jetty, etc.). Once the fuel is exhausted, the reactor will be lifted from the vault and shipped back to a central facility for refueling. The cost of the return shipment will be higher than the initial delivery because of the presence of spent fuel. Technically, this shipment should be an entirely straightforward activity. Since 1971 there have been at least 25,000 cargoes of used fuel transported, covering many millions of kilometers on both land and sea, including sea voyages transporting more than 4000 casks, each of about 
100 tons. In the U.S. there have been over 3000 shipments of commercially generated spent nuclear fuel without causing any radiological releases to the environment or harm to the public [19].

Table 4 provides the summary detail for our capital cost projections. Our estimates include appropriate contingencies for each of the cost categories based on the granularity of estimate available to us at this stage of NB maturity. Those contingencies vary from $10 \%$ on components that have current quotes or estimates to $40 \%$ for those that have only limited design detail. Excluding development and regulatory design/approval costs and FOAK costs, we arrive at a prediction of roughly $30 \mathrm{M}$ USD for NOAK capital costs and carry $3000 \mathrm{USD} / \mathrm{kW}$ (10 MWe NB) for our base case LCOE and LCOH calculations.

Table 4. Breakdown of NB capital costs, including contingencies.

\begin{tabular}{|c|c|c|c|}
\hline Category & $\begin{array}{l}\text { Projection } \\
\text { (in M USD) }\end{array}$ & Contingency & Notes \\
\hline Site work & 1.05 & $25 \%$ & $\begin{array}{l}\text { Includes earth work, foundation, } \\
\text { vault, service building, concrete, } \\
\text { asphalt, fencing, entry. Assumes } \\
\text { commercial (non-nuclear) } \\
\text { construction. }\end{array}$ \\
\hline $\begin{array}{l}\text { Permanent } \\
\text { equipment }\end{array}$ & 8.90 & $10 \%$ & $\begin{array}{l}\text { Includes electric transformer, } \\
\text { lightning protection system, power } \\
\text { conversion unit, back-up } \\
\text { (non-safety) diesel and other } \\
\text { miscellaneous equipment. Assumes } \\
\text { commercial (non-nuclear) } \\
\text { construction. }\end{array}$ \\
\hline $\begin{array}{l}\text { Fabrication of } \\
\text { nuclear reactor }\end{array}$ & 16.20 & $40 \%$ & $\begin{array}{l}\text { Includes all reactor systems, } \\
\text { structures and components, such as } \\
\text { core internals, control system, } \\
\text { reflector, shielding, vessel, external } \\
\text { package, supports, intermediate heat } \\
\text { exchanger, etc. Excludes cost of fuel. }\end{array}$ \\
\hline Transportation & 1.05 & $25 \%$ & $\begin{array}{l}\text { Includes shipment of all equipment } \\
\text { to site and reactor shipment back to } \\
\text { central refueling facility. Based on } \\
1000 \text { miles distance between site and } \\
\text { facility. }\end{array}$ \\
\hline Installation & 1.15 & $35 \%$ & $\begin{array}{l}\text { Includes crane, field logistics } \\
\text { equipment, site trailer, labor and site } \\
\text { management, engineering startup. } \\
\text { Does not include ASME- or } \\
\text { NRC-related testing. }\end{array}$ \\
\hline $\begin{array}{l}\text { Refueling site } \\
\text { costs }\end{array}$ & 1.60 & $35 \%$ & $\begin{array}{l}\text { Includes crane, field logistics } \\
\text { equipment, labor and site } \\
\text { management required for loading } \\
\text { up and shipping the reactor. } \\
\text { Excludes cost of fresh fuel reload } \\
\text { and refurbishment if necessary. }\end{array}$ \\
\hline Total & $\sim 30$ & & Figure used in the base case \\
\hline
\end{tabular}

Some of the above capital costs are incurred only once (e.g., the fabrication costs, the site preparation, the vault, the service building, etc.), while others are incurred in each irradiation cycle (e.g., ship the reactor to/from the site). For simplicity, we roll them all up into a single initial cost (once again, $30 \mathrm{M}$ USD per NB in the base case), and level it over the 20-year economic life of the NB using the appropriate capital recovery factor. The cost 
of decommissioning is assumed to be half of the initial capital cost and is incurred at the end of the NB lifetime, so it is levelized using a sinking fund factor.

\section{Results}

For the baseline case assumptions in Table 3, the LCOE and LCOH are 85 USD/MWh and 30 USD/MWh (or 8.7 USD/MMBTU), respectively. This is encouraging because such figures are well within the acceptable cost ranges discussed in Section 3. However, since the uncertainties in the many assumptions made are substantial, we must perform a sensitivity analysis. Therefore, eight input parameters are varied (one at a time) within the following broad intervals:

- Electric power: 1 to $20 \mathrm{MW}$

- Fuel enrichment: $5 \%$ to $20 \%$

- Discharge burnup: 2 to $30 \mathrm{MWd} / \mathrm{kg}_{\mathrm{U}}$. Discharge burnup generally increases with enrichment, and the nature of that relationship depends strongly on the reactor design of interest. For simplicity here we treat the two quantities as independent to cover the full design space.

- Refueling interval: 3 to 10 years

- NB capital cost (excluding fuel): 1000 to $10,000 \mathrm{USD} / \mathrm{kW}$

- \# of FTEs for O\&M: 2 to 15

- Discount rate: 2 to $15 \%$ / year

- Capacity factor: $50 \%$ to $98 \%$. The lower end of this range might be typical of a site that does not require heat and/or electricity $24 / 7$.

The results for the LCOE are shown in Figures 8-15. The results for LCOH are qualitatively identical because $\mathrm{LCOH}=\mathrm{LCOE} \times$ thermal efficiency. Briefly, the effect of electric power on LCOE is quite dramatic, whether the total capital cost is fixed (no scaling) or the unit cost is fixed (linear scaling), as shown in Figure 8a,b, respectively. Maximizing the electric power is clearly beneficial to the NB economics.

The fuel cost tends to be relatively high in micro-reactors (e.g., relative to LWRs), and it increases substantially with increasing fuel enrichment and decreasing fuel burnup, as shown in Figures 9 and 10, respectively. Figure 11 suggests that long refueling intervals do not reduce cost, in fact they increase it slightly because of the interest paid on the fuel. Moreover, the mass of fuel in the core and therefore the core dimensions are inversely proportional to refueling interval, for given core power and discharge burnup, so it is likely that long refueling intervals will result in substantially larger and thus costlier reactors.

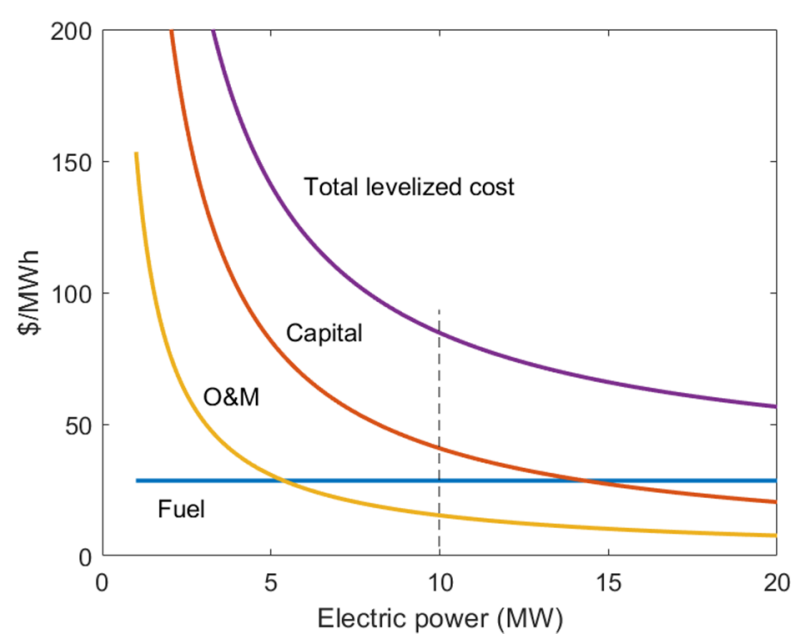

(a)

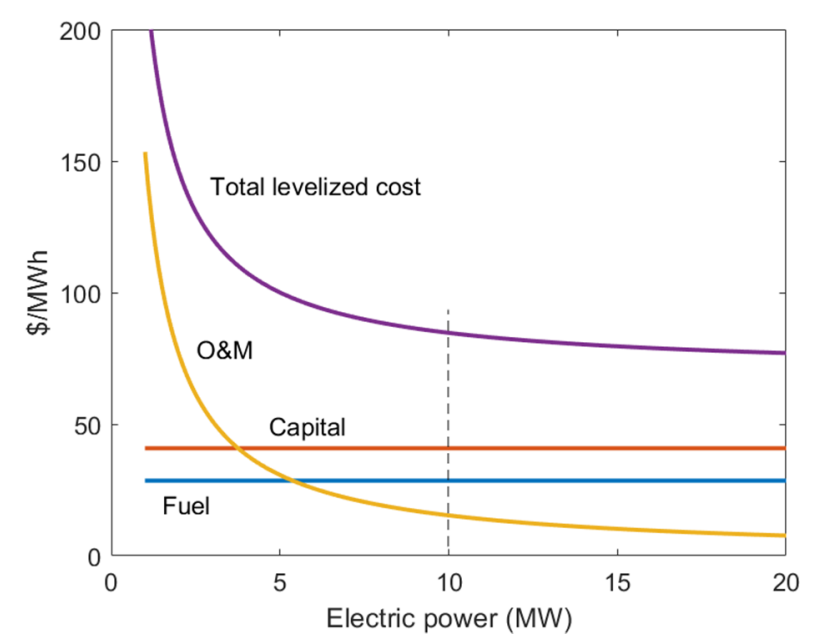

(b)

Figure 8. NB levelized electricity costs vs. electric power for (a) fixed total capital cost (USD) and (b) fixed unit cost (USD/kW). 


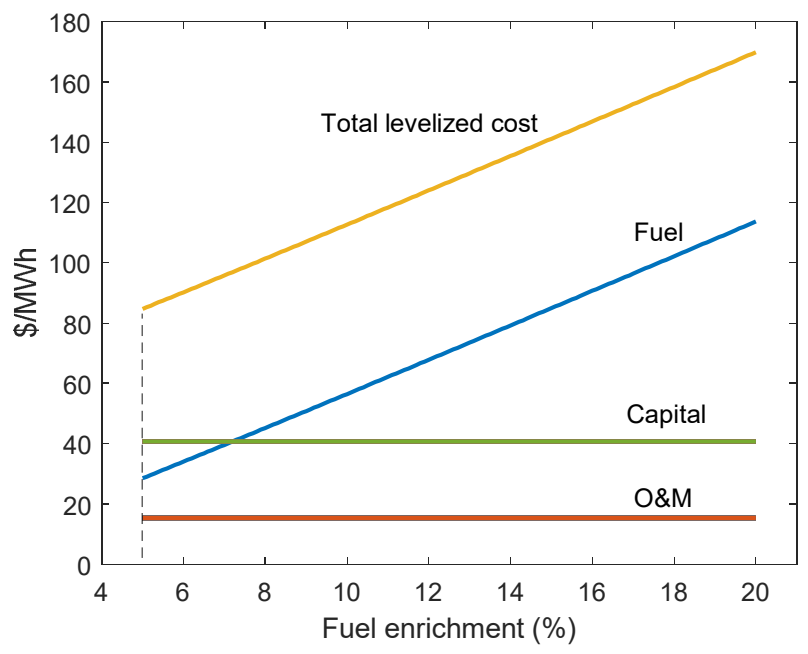

Figure 9. NB levelized electricity costs vs. fuel enrichment.

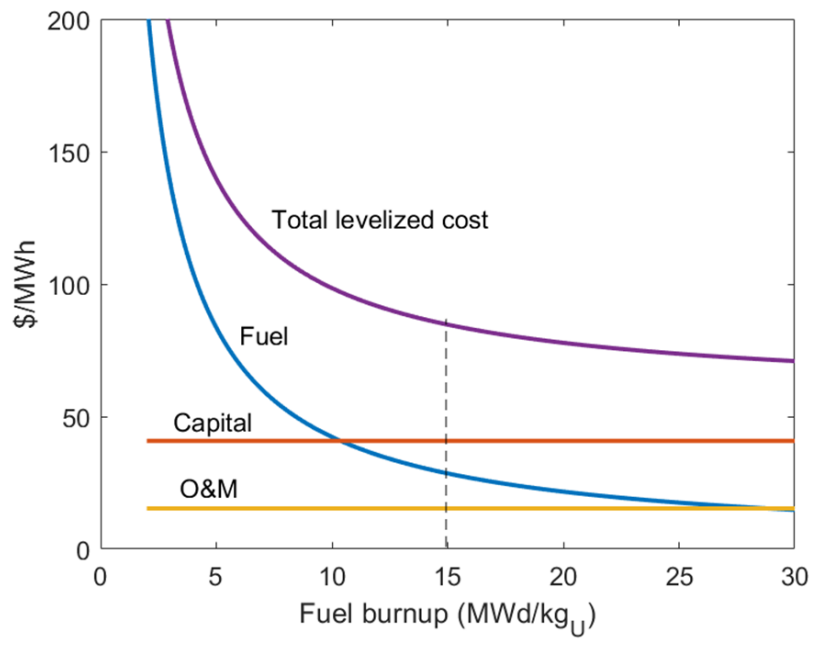

Figure 10. NB levelized electricity costs vs. fuel burnup.

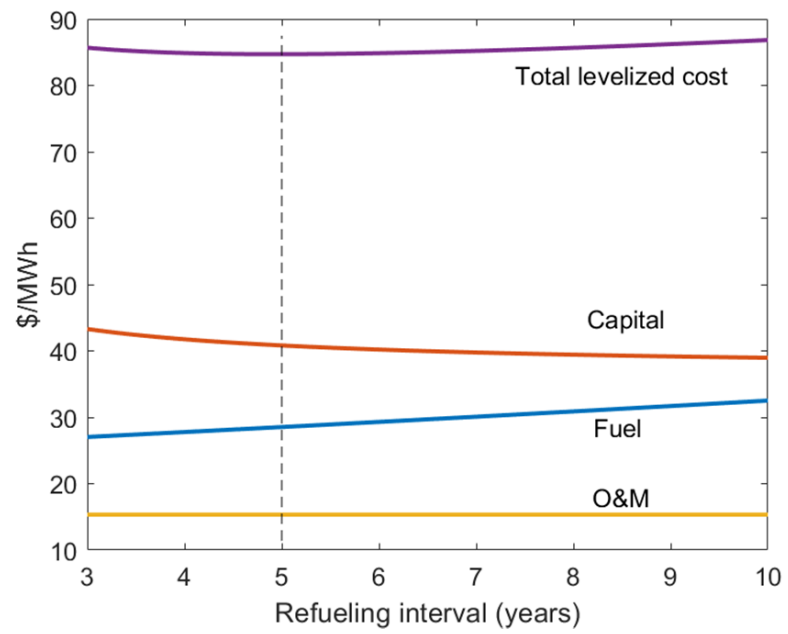

Figure 11. NB levelized electricity costs vs. refueling interval. 


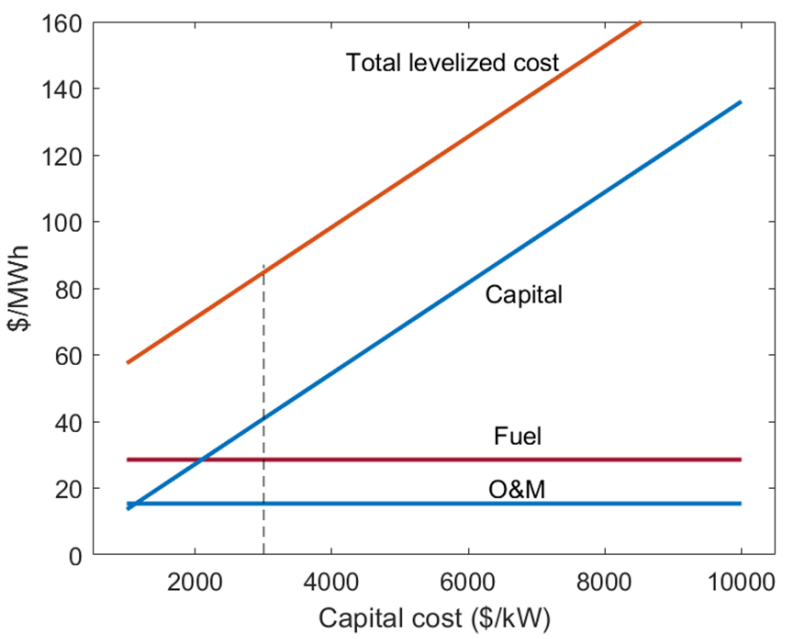

Figure 12. NB levelized electricity costs vs. capital cost.

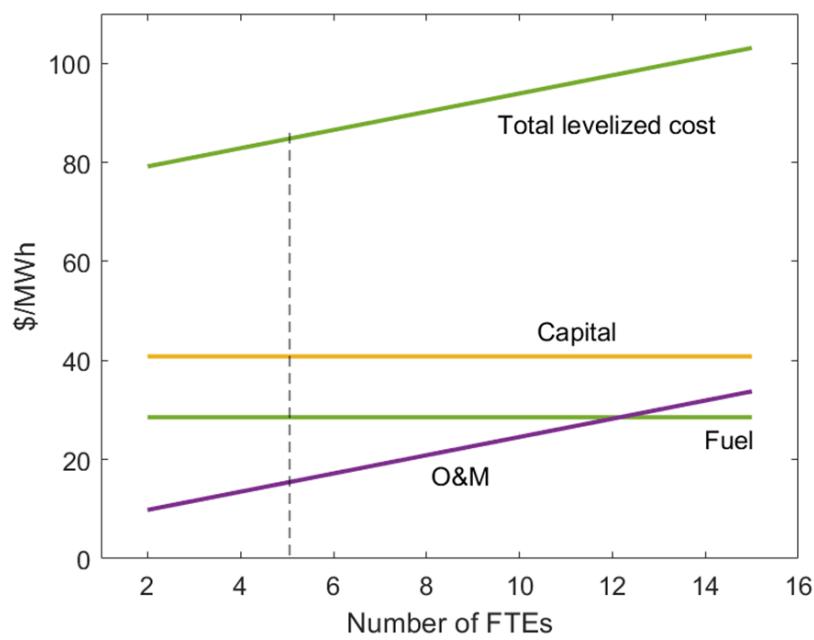

Figure 13. NB levelized electricity costs vs. FTEs.

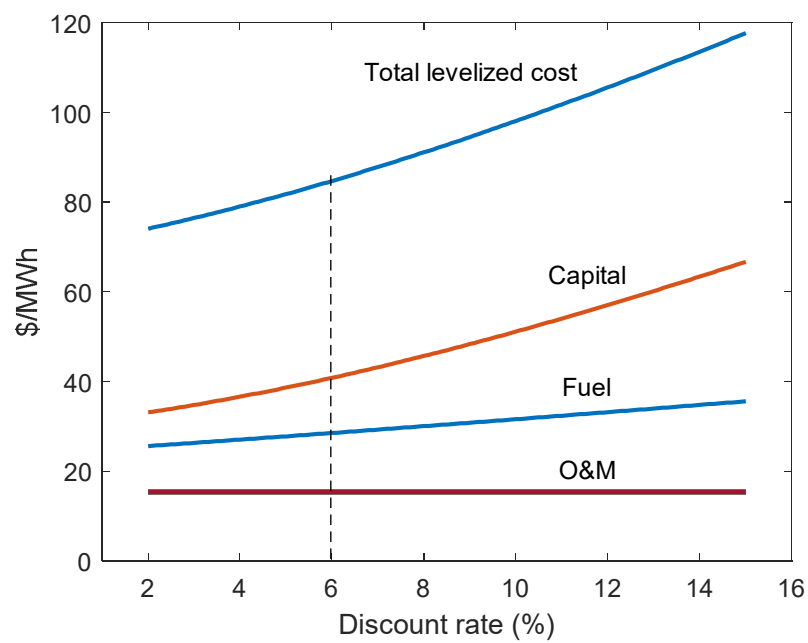

Figure 14. NB levelized electricity costs vs. discount rate. 


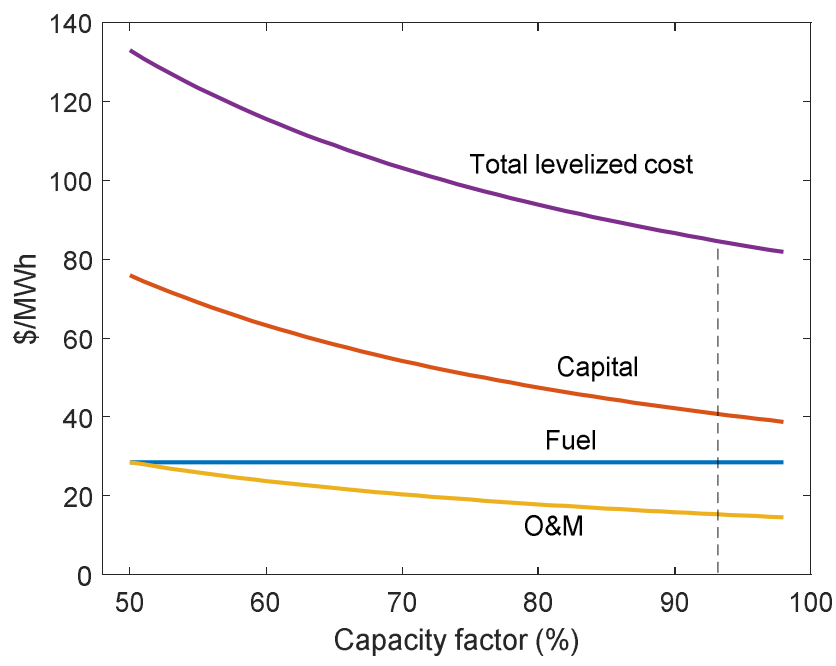

Figure 15. NB levelized electricity costs vs. capacity factor.

The cost of NB electricity increases strongly with increasing NB capital cost (Figure 12), as expected, but to a lesser degree with increasing number of FTEs (Figure 13). Figure 14 shows that the discount rate strongly affects the capital costs and moderately the fuel costs. Lastly, the effect of capacity factor is shown in Figure 15, confirming the importance of running the NB continuously and reliably for good economics.

We conclude the sensitivity analysis by noting that design choices matter when it comes to cost, and the cost of a small reactor can easily escalate to a level that will make it non-competitive in large markets. To illustrate this point, we calculated the LCOE of a notional micro-reactor design with economically unfavorable characteristics, i.e., low electric power ( $2 \mathrm{MW})$, high capital cost $(7000 \mathrm{USD} / \mathrm{kW})$, expensive fuel fabrication $\left(10,000 \mathrm{USD} / \mathrm{kg}_{\mathrm{U}}\right)$, relatively high enrichment (15\%), intermediate burnup (50 MWd $\left./ \mathrm{kg}_{\mathrm{U}}\right)$, long refueling interval (20 years) and relatively high number of employees (15 FTEs, equivalent to three people onsite 24/7). The results are shown in Figure 16: all three cost components are significantly higher, and the bottom line is an unattractive LCOE of nearly $335 \mathrm{USD} / \mathrm{MWh}$ vs. $85 \mathrm{USD} / \mathrm{MWh}$ for the baseline case. To be fair, microreactors can be competitive in certain niche markets even at $>300 \mathrm{USD} / \mathrm{MWh}$, but certainly not in the large markets this study is focused on.

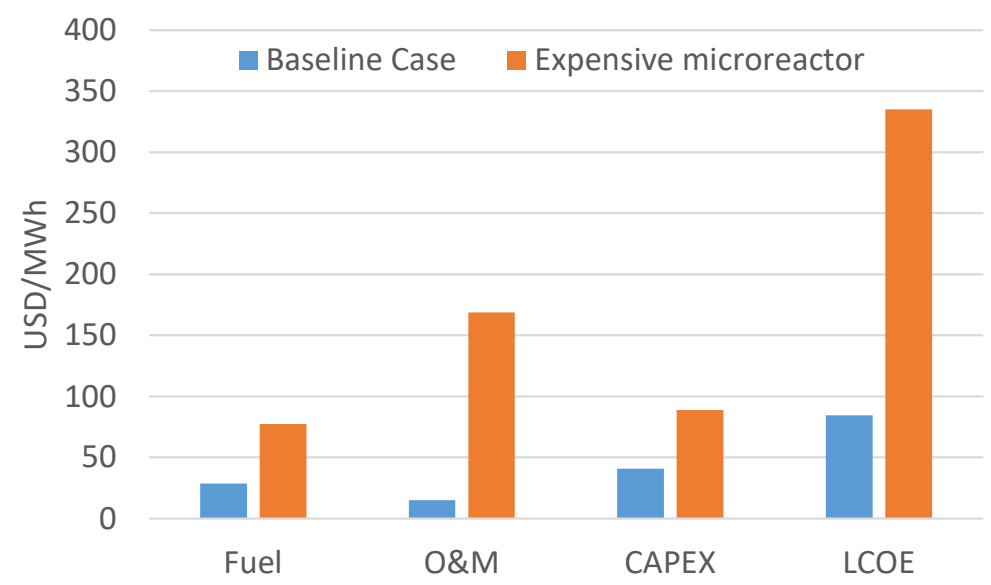

Figure 16. Levelized costs of fuel, O\&M and capital costs (CAPEX) for the baseline case of Table 3, and a notional expensive micro-reactor design. 


\section{Conclusions}

If nuclear is to play a meaningful role in the decarbonization of the U.S. and global economy, its development and deployment paradigms have to evolve towards smaller, simpler, more flexible and affordable reactors. In this paper we focused on nuclear batteries, a new class of compact micro-reactors that are factory-fabricated, transportable, plug-andplay and operating autonomously. If they can be demonstrated and commercially deployed well within the end of the decade, as is currently planned, NBs appear to be ideally positioned to provide heat and electricity to myriad of energy users across all sectors of the economy. The NB success in these large markets will depend crucially on their economic competitiveness with alternatives. Here we determined the generic NB cost targets for the markets of interest to be 20-50 USD/MWh $(6-15$ USD/MMBTU) and 70-115 USD/MWhe for heat and electricity, respectively. Then we performed a bottom-up parametric analysis of the levelized cost of heat and electricity from NBs; this analysis suggests that the cost targets are within reach of the NBs if (i) the reactor power is maximized within the NB constraints (e.g., road transportability, passive decay heat removal), (ii) staff is in the 0.5-1.5 FTE/MW range, (iii) fuel enrichment is $<10 \%$ and fuel burnup is $>10 \mathrm{MWd} / \mathrm{kg}_{\mathrm{U}}$, (iv) NB capital cost is $<5000 \mathrm{USD} / \mathrm{kW}$, and (v) discount rate is $<10 \% /$ year. We found no cost incentive for very long refueling intervals ( $>10$ years). Lastly, we showed that the cost of a small reactor can easily escalate if its design parameters are not consistent with the above guidelines.

Author Contributions: Conceptualization, software and original draft preparation, J.B.; methodology, validation, formal analysis, investigation, review and editing, all authors. All authors have read and agreed to the published version of the manuscript.

Funding: This research received no external funding.

Institutional Review Board Statement: Not applicable.

Informed Consent Statement: Not applicable.

Conflicts of Interest: The authors declare no conflict of interest.

\section{Appendix A. MATLAB Script for Calculation of LCOE and LCOH}

$\% \%$ reactor parameters

We $=10 ; \%$ electric output (MW)

eta $=0.35$; \%thermal efficiency

$\mathrm{Q}=\mathrm{We} / \mathrm{eta}$; \%reactor power (MW)

$\mathrm{CF}=0.93$; \%onsite capacity factor $(<100 \%$ bc of loss of availability or load following)

$\mathrm{T}=5$; \%operating refueling time between refueling outages (yrs)

T_RS=0.5; \%time for cooldown, shipment back/forth to central facility for refueling and servicing (yrs)

$\mathrm{r}=0.06$; \%annual discount rate

$\mathrm{BU}=15$; \%discharge burnup (MWd/kg_HM)

q3 $=1 \mathrm{e} 3{ }^{*} \mathrm{BU} . /\left(365^{*} \mathrm{~T}^{*} \mathrm{CF}\right) ; \%$ specific power in the fuel $\left(\mathrm{kW} / \mathrm{kg} \_\mathrm{HM}\right)$

$\mathrm{Mp}=1 \mathrm{e} 3^{*} \mathrm{Q} . / \mathrm{q} 3 ; \%$ mass of fuel $\left(\mathrm{kg}_{-} \mathrm{HM}\right)$

$\% \%$ fuel parameters

$\mathrm{f}=0.711 \mathrm{e}-2$; \%uranium feed enrichment

$\mathrm{p}=5^{*} 1 \mathrm{e}-2$; \%reactor fuel enrichment

$\mathrm{t}=0.22 \mathrm{e}-2$; \%tail enrichment

$\mathrm{V} p=\left(1-2^{*} \mathrm{p}\right)^{*} \log ((1-\mathrm{p}) . / \mathrm{p}) ; \%$ value function for enriched fuel

$\mathrm{Vf}=\left(1-2^{*} \mathrm{f}\right)^{*} \log ((1-\mathrm{f}) / \mathrm{f}) ; \%$ value function for uranoum feed

$V t=\left(1-2^{*} t\right)^{*} \log ((1-t) / t) ; \%$ value function for uranium tail 
$\mathrm{Mf}=(\mathrm{p}-\mathrm{t}) . /(\mathrm{f}-\mathrm{t})^{*} \mathrm{Mp} ; \%$ amount of uranium feed $(\mathrm{kg})$

$\mathrm{Mt}=\mathrm{Mf} . *(\mathrm{p}-\mathrm{f}) . /(\mathrm{p}-\mathrm{t}) ; \%$ amount of uranium tail $(\mathrm{kg})$

$\mathrm{SWU}=\left(\mathrm{Mp}{ }^{*} \mathrm{Vp}+\mathrm{Mt}{ }^{*} \mathrm{Vt}-\mathrm{Mf} .{ }^{*} \mathrm{Vf}\right) . / \mathrm{Mp} ; \% \mathrm{SWU}$ per unit mass of uranium product(SWU/kg_HM)

$\% \%$ costs

$\%$ FUEL

C_yc $=40 / 0.848 / 0.4536 ; \%$ cost of U3O8 (\$/kg_HM)

C_conv $=6$; \%cost of conversion $\left(\$ / \mathrm{kg}_{-} \mathrm{HM}\right)$

C_SWU $=160 ; \%$ cost of enrichment $(\$ / S W U)$

C_F $=500 ; \%$ cost of fuel fabrication $\left(\$ / \mathrm{kg} \_\mathrm{HM}\right)$

C_uf $=\left(C_{-} \text {yc }+ \text { C_conv }\right)^{*} \mathrm{Mf} ; \%$ uranium feed + conversion cost $(\$)$

C_en $=S W U .{ }^{*} \mathrm{Mp}^{*} \mathrm{C} \_$SWU; \%enrichment cost $(\$)$

C_fab $=C_{-} F^{*} \mathrm{Mp} ; \%$ fabrication cost $(\$)$

CRF_F=r.*(1+r).^T./((1+r).^T-1); \%A/P capital recovery factor for fuel

SNF_fee $=0.001 ; \%$ spent nuclear fuel disposal fee in the US $(1 \mathrm{mil} / \mathrm{kWh})$

$\% \mathrm{O} \& \mathrm{M}$

FTE $=5$; \% number of FTEs for O\&M

Sal=150e3; \%annual salary fully loaded $(\$ / y r)$

OMfixed=500e3; \%fixed O\&M (\$/yr)

C_OM=FTE*Sal+OMfixed; \%annual O\&M cost $(\$ / y r)$

$\%$ CAPITAL

ICC $=30 \mathrm{e} 6$; \%total NB capital cost (\$), includes reactor and power conversion unit fabrication, transportation, installation and connection, site preparation and service building. Excludes fuel costs.

ICCs=ICC $/\left(1 \mathrm{e} 3^{*} \mathrm{We}\right) ; \%$ unit capital cost $(\$ / \mathrm{kW})$

$\mathrm{T} \_\mathrm{R}=20$; \%reactor economic lifetime (yr)

CRF_R=r.*(1+r).^T_R./((1+r).^^T_R-1); \%A/P capital recovery factor for capital cost (excluding decommissioning)

$\mathrm{SFF}=\mathrm{r} . /\left((1+\mathrm{r}){ }^{\wedge} \mathrm{T} \_\mathrm{R}-1\right) ; \% \mathrm{~A} / \mathrm{F}$ sinking fund factor for decommissioning

$\mathrm{DEC}=1 / 2^{*} \mathrm{ICC}$; \%decommissioning cost assumed to be $1 / 2$ of capital cost (\$)

\%levelized costs

LCOF $=\left((\right.$ C_uf + C_en+C_fab $) .{ }^{*}$ CRF_F $) . /\left(1 e 3^{*} \mathrm{We}^{*} \mathrm{CF}^{*} 8760\right)+\mathrm{SNF}$-fee \%levelized cost of fuel $(\$ / \mathrm{kWh})$

LCOOM=C_OM. $/\left(1 \mathrm{e}^{*} \mathrm{We}^{*} \mathrm{CF}^{*} 8760\right) \%$ levelized cost of O\&M $(\$ / \mathrm{kWh})$

LCOP $=\left(\right.$ ICC. ${ }^{*}$ CRF_R+DEC. ${ }^{*}$ SFF $) . /\left(1 \mathrm{e}^{*} \mathrm{We}^{*} \mathrm{CF}^{*} 8760\right)^{*}\left(1+\mathrm{T} \_\mathrm{RS} / \mathrm{T}\right)$ \%levelized capital cost $(\$ / \mathrm{kWh})$ (corrected for offsite downtime due to refueling and servicing)

$\mathrm{LCOE}=\mathrm{LCOF}+\mathrm{LCOOM}+\mathrm{LCOP} ; \%$ levelized cost of electricity $(\$ / \mathrm{kWh})$

$\mathrm{LCOH}=\mathrm{LCOE} *$ eta; \%levelized cost of heat $\left(\$ / \mathrm{kWh} \_\mathrm{t}\right)$

\section{References}

1. Brookhaven National Laboratory. Regulatory Review of Micro-Reactors-Initial Considerations; BNL-212380-2019-INRE; Brookhaven National Laboratory: Brookhaven, NY, USA, 2020.

2. Nichol, M. Cost Competitiveness of Micro-Reactors for Remote Markets; Nuclear Energy Institute (NEI): Washington, DC, USA, 2019.

3. Office of the Secretary of Defense Strategic Capabilities Office. Request for Solutions, Pele Program Phase I; Office of the Secretary of Defense Strategic Capabilities Office, Washington Headquarters Service: Washington, DC, USA, 2019. 
4. $\quad$ Nuvia. Market and Technical Assessment of Micro Nuclear Reactors; Nuvia: Warrington, UK, 2016.

5. Gilbert, A.Q.; Bazilian, M.D. Can Distributed Nuclear Power Address Energy Resilience and Energy Poverty? Joule 2020, 4, 1839-1843. [CrossRef] [PubMed]

6. AeroJet General Nucleonics. The ML-1 Design Report, Report IDO-28550; AeroJet General Nucleonics: San Ramon, CA, USA, 1960.

7. McClure, P.; Poston, D.; Rao, D.V.; Reid, R. Design of Megawatt Power Level Heat Pipe Reactors; LA-UR-15-28840; Los Alamos National Laboratory: Los Alamos, NM, USA, 2015.

8. McClure, P.; Poston, D.; Gibson, M.A.; Mason, L.S.; Robinson, R.C. Kilopower Project: The KRUSTY Fission Power Experiment and Potential Missions. Nucl. Technol. 2020, 206, S1-S12. [CrossRef]

9. Levinsky, A.; van Wyk, J.; Arafat, Y.; Smith, M. Westinghouse eVinci Reactor for Off-Grid Markets. Trans. Am. Nucl. Soc. 2018, 119, 931-934.

10. Radiant Nuclear. Available online: https:/ / radiantnuclear.com/ (accessed on 16 July 2021).

11. Smil, V. Power Density-A Key to Understand Energy Sources and Uses; MIT Press: Cambridge, MA, USA, 2016.

12. Denholm, P.; Hand, M.; Jackson, M.; Ong, S. Land-Use Requirements of Wind Power Plants in the US; NREL/TP-6A2-45834; NREL: Golden, CO, USA, 2009.

13. Mills, M. Testimony before the US Senate Committee on Energy and Natural Resources; Dirksen Senate Office Building: Washington DC, USA, 2021. Available online: https://www.energy.senate.gov/services / files/CA2C8537-4D93-4424-BBA4-2FBA1CF2E4B9 (accessed on 16 July 2021).

14. ArcelorMittal. Available online: https:/ / corporate.arcelormittal.com/media/case-studies/steel-is-the-power-behind-renewableenergy (accessed on 16 July 2021).

15. Brandl, P.; Bui, M.; Hallett, J.P.; Dowell, N.M. Beyond 90\% capture: Possible, but at what cost? Int. J. Greenh. Gas Control 2021, 105, 103239. [CrossRef]

16. Smith, E.; Morris, J.; Kheshgi, H.; Teletzke, G.; Herzog, H.; Paltsev, S. The Cost of $\mathrm{CO}_{2}$ Transport and Storage in Global Integrated Assessment Modeling. In Proceedings of the 15th Greenhouse Gas Control Technologies Conference, Abu Dhabi, UAE, 15-18 March 2021.

17. Annual Energy Outlook 2021. Available online: https://www.eia.gov/outlooks/aeo/ (accessed on 16 July 2021).

18. Inside the World's Smartest Power Plant: What T-Point 2 Says about the State of the Autonomous Power Plant and How It Can Support the Smart Grid. Available online: https:/ / electricenergyonline.com/energy/news/product-highlights/886043 /inside-the-world-s-smartest-power-plant-what-t-point-2-says-about-the-state-of-the-autonomous-power-plant-and-how-itcan-support-the-smart-grid.htm (accessed on 16 July 2021).

19. Transport of Radioactive Materials. Available online: https://www.world-nuclear.org/information-library/nuclear-fuel-cycle/ transport-of-nuclear-materials/transport-of-radioactive-materials.aspx (accessed on 16 July 2021). 